\title{
CULTURA NAS INSTITUIÇÕES DE SAÚDE E SUAS RELAÇÕES COM A IDENTIDADE INDIVIDUAL
}

Sérgio Ribeiro Santos ${ }^{1}$

RESUMO: O estudo tem como objetivo fazer uma análise conceitual dos aspectos que envolvem a cultura nas instituições de saúde e a identidade individual dos profissionais envolvidos com o ato de cuidar dos pacientes. Para tanto, busca enfocar os seguintes assuntos: cultura organizacional; o processo de construção das instituições de saúde e a cultura organizacional; a identidade do sujeito na organização; o papel da cultura individual nas instituições de saúde.

PALAVRAS-CHAVE: Cultura; Instituições de saúde.

\section{CULTURE IN THE INSTITUTION OF HEALTH AND THEIR RELATIONSHIPS WITH THE INDIVIDUAL IDENTITY}

\begin{abstract}
The study has as objective to do a conceptual analysis of the aspects that involve culture in health institutions and professionals' individual identity involved with patients' caring action. Thus, it tries to focus on the following subjects: organizational culture; the construction process of health institutions and the organizational culture; the subject's identity in the organization; the role of individual culture in health institutions.
\end{abstract}

KEYWORDS: Culture; Health facilities.

\section{LA CULTURA EN LAS INSTITUCIONES DE SALUD Y SUS RELACIONES CON LA IDENTIDAD INDIVIDUAL}

RESUMEN: Este trabajo tiene por objetivo hacer un análisis conceptual de los aspectos que involucran la cultura en las instituciones de salud y la identidad individual de los profesionales involucrados con el acto de cuidar de los pacientes. Para tal fin, busca enfocar los siguientes asuntos: la cultura orgánica; el proceso de construcción de las instituciones de salud y la cultura orgánica; la identidad del sujeto en la organización; el papel de la cultura en las instituciones de salud.

PALABRAS CLAVE: Cultura; Instituciones de salud. 


\section{INTRODUÇÃO}

Atualmente, tem-se enfatizado a noção de cultura, tanto nos estudos das organizações, quanto nas práticas gerenciais. Trata-se de um avanço em relação às concepções existentes no século passado, por volta dos anos 60 e 70, quando as atenções estavam centralizadas no comportamento econômico dos atores organizacionais e nos aspectos da racionalização do trabalho. A preocupação atual consiste em identificar o modo como as pessoas se relacionam nas organizações e a maneira como reagem às emoções e à subjetividade. Muitos autores vêm estudando essa temática ${ }^{(1-3)}$.

A retomada dos estudos da cultura organizacional, em termos de novas abordagens, vem desvendar inúmeras dimensões e identificar relações de intersubjetividade e compromisso com o trabalho. Por sua vez, as empresas têm, em sua origem, limitações oriundas das organizações ocidentais, cuja preocupação está focalizada na melhoria dos níveis de produtividade, em comparação ao extraordinário sucesso do modelo de gestão japonês.

Não é de se estranhar que o grande destaque na cultura empresarial surgiu, de um lado, da associação com a qualidade declinante da indústria norteamericana $^{(4)}$, e de outro lado, fortaleceu-se com o culto às empresas japonesas como modelo de organização que maximiza o consenso e o comprometimento, ainda que as noções de pós-modernidade estejam vinculadas à "japonização" do mundo industrial, que se fundamenta na habilidade de gerenciar o coletivo ${ }^{(5)}$.

A exemplo das organizações em geral, na área de saúde o modelo de gestão se incorporou ao do mundo industrial. Todavia, as peculiaridades inerentes à prestação de serviço em saúde levaram tais instituições a buscarem adequações gerenciais. Isso ocorreu, essencialmente, em vista das diferentes culturas contidas no staff administrativo entre os médicos, enfermeiros e outros profissionais que constituem a diversidade ou pluralidade de profissionais que se unem para cuidar da saúde das pessoas.

Foi esse contexto que despertou o nosso interesse em estudar a cultura nas instituições de saúde, com o propósito de compreendê-la e, assim, melhorar o gerenciamento dessas organizações. Cultura se trata de um conceito que envolve dimensões imprevisíveis e intangíveis, embora se admita que seja racionalmente apreensável. Em outras palavras, a noção de cultura aplicada ao contexto das instituições de saúde possibilita a integração de aspectos subjetivos e simbólicos voltados para o gerenciamento estratégico de ações envolvidas. Quando se propõe administrar o simbólico e buscar o controle das pessoas comprometidas, o conceito de cultura organizacional pretende unir as ações de saúde ao imaginário das pessoas.

Diante do exposto, passamos a refletir sobre a relação que há entre a identidade individual e a cultura nas instituições de saúde. Portanto, este estudo tem o objetivo de fazer uma análise conceitual dos aspectos que envolvem a cultura nas instituições de saúde e a identidade individual dos profissionais envolvidos com o ato de cuidar dos pacientes. Espera-se, com isso, contribuir para a compreensão dos fenômenos culturais que ocorrem no âmbito dessas organizações.

\section{CULTURA ORGANIZACIONAL}

Existem na literatura muitos conceitos de cultura. No âmbito da temática em análise, a cultura de uma organização pode ser delineada através de normas, crenças, valores e padrões centrais que estruturam a dinâmica organizacional ${ }^{(6-8)}$. Em outras palavras, podese afirmar que toda instituição, em qualquer ramo de atividade ou área de atuação, possui uma cultura própria que delineia seu ambiente e suas relações sociais.

A cultura organizacional é um conjunto de pressupostos básicos que um grupo inventou, descobriu ou desenvolveu ${ }^{(9)}$. Dessa forma, o grupo aprende como lidar com os problemas de adaptação externa e integração interna. Por funcionarem bem, esses pressupostos passam a ser considerados válidos e ensinados aos novos membros da organização como a forma correta de perceber, pensar e sentir em relação a esses problemas. Isso significa que as crenças e valores acabam entrando no nível de inconsciência das pessoas, sendo aceitos como verdades inquestionáveis. Portanto, a organização é um processo dinâmico e contínuo de aprendizagem na formação cultural, que é transmitido às futuras gerações. Ou seja, ele se encontra na essência da formação histórica da cultura organizacional.

Dentro dessa perspectiva, a cultura organizacional pode ser compreendida como um conjunto de valores, crenças e sentimentos ${ }^{(10)}$. Uma vez vinculados aos mecanismos que os expressam e os difundem (tais como: mitos, símbolos, metáforas e rituais), são herdados, compartilhados e disseminados dentro de um grupo de pessoas que se distingue de outros grupos por suas peculiaridades culturais.

Portanto, a cultura de uma organização é 
constituída por um conjunto de crenças, valores e pressupostos básicos implantados pelos seus fundadores. Com o passar do tempo, esses valores vão sendo aperfeiçoados e disseminados na organização por meio de diversos mecanismos, tais como: os líderes atribuem importância a algo e depois tentam implantar e controlar; a forma como os membros de uma organização reagem a eventos críticos, carregados de emoção; as crises organizacionais; os critérios utilizados para recrutamento de funcionários; o desenho e a estrutura da organização; as declarações formais da filosofia organizacional e seus credos ${ }^{(11)}$. Como se observa, a cultura organizacional é criada pelos fundadores e líderes da empresa e mantida, principalmente, por meio de políticas de recursos humanos.

Há, na literatura, uma pluralidade de conceitos sobre cultura organizacional. E essa diversidade leva ao questionamento de estudos que consideram aspectos da cultura organizacional significativamente diferentes e diversificados no âmbito da própria conceituação de cultura, bem como na metodologia de investigação a ser adotada e nos objetivos que tais estudos pretendem atingir.

As variáveis organizacionais, a exemplo da estrutura, regras, políticas, objetivos, missão, descrição de cargos e procedimentos operacionais, são fatores que delimitam e fundamentam a cultura de uma organização e também sua percepção pelos empregados $^{(12-13)}$. Assim, a cultura organizacional pode ser entendida como um processo de construção e compartilhamento da realidade organizacional, através de eventos, expressões e manifestações culturais que são fatores significativos para os empregados ${ }^{(14)}$. Dessa forma, a adequação à cultura vigente permite a conformidade com as regras e valores estabelecidos, dificultando o surgimento de novas variantes culturais.

Por outro lado, sob a perspectiva simbólica, a cultura organizacional é definida como um conjunto de pressupostos básicos que os grupos desenvolvem para lidar com os problemas de adaptação externa e integração interna ${ }^{(13)}$. Na realidade, a cultura é imprescindível para o desenvolvimento das instituições. É preciso também levar em consideração que as pessoas se relacionam entre si e são orientadas na organização, de acordo com a percepção da cultura dominante. A partir dessa realidade, a compreensão da cultura torna-se vital para se analisar a dinâmica organizacional e seus constituintes.

No que diz respeito à compreensão da cultura organizacional, um gerente pode destacar os valores positivos já existentes e promover novos valores exigidos pela organização, como qualidade, eficácia, eficiência, comprometimento, cooperação e respeito. Portanto, a compreensão da cultura na organização é fundamental para o gestor poder trabalhar os fatores positivos que favoreçam a efetiva mudança cultural. Quando a instituição possui uma cultura voltada para mudanças inovadoras, fica mais fácil promovê-la. Mas, quando existe na organização uma cultura rígida e pouco inovativa, o gestor terá enormes dificuldades.

\section{O PROCESSO DE CONSTRUÇÃO DAS INSTITUIÇÕES DE SAÚDE E A CULTURA ORGANIZACIONAL}

As pessoas que integram uma organização têm características individuais e coletivas na sua maneira de pensar e agir em sua convivência no dia-a-dia do trabalho. A forma como as pessoas pensam, suas condutas e símbolos têm um significado concreto e fazem parte da cultura organizacional. Tais pressupostos são encontrados em qualquer instituição, inclusive na área de saúde.

As variações culturais existentes nas instituições estão ligadas a diferentes tipos de pessoas que as compõem. De fato, ao longo do processo histórico, a mudança social afetou o desenvolvimento da cultura organizacional, a exemplo dos hospitais. Nos primórdios da era cristã, estes eram os locais onde se recebiam enfermos pobres, incuráveis ou insanos para serem cuidados, geralmente, por religiosos e leigos. Eram entidades assistenciais, de cultura religiosa, dentro de uma estrutura em que a proteção e o amor ao próximo constituíam os seus fundamentos.

Atualmente, o hospital é focalizado como uma instituição de prestação de serviços. Embora seja visto como instituição humanitária, enfrenta os mesmos problemas existentes nas empresas industriais. Talvez a instituição hospitalar tenha uma cultura organizacional mais complexa, principalmente, depois que assumiu um caráter mais profissional. Como se sabe, o hospital é composto por uma diversidade de trabalhadores, que vão desde os médicos e enfermeiros aos diferentes profissionais da área de saúde. Há, além disso, outros profissionais como terapeutas ocupacionais, advogados, engenheiros, contadores, administradores, técnicos em informática, profissionais de marketing e pessoal de apoio que atua na limpeza, lavanderia, manutenção e outros. 
Nesse ambiente de elevado grau de complexidade quanto aos seus procedimentos, é comum haver conflitos entre as diferentes culturas profissionais existentes na organização. Isso se explica em virtude da formação de uma cultura profissional própria com trajetória diversificada, ou seja, as pessoas, geralmente, vêm de outras instituições com visões e experiências diferentes da que existe na organização em que trabalham.

A grande diferença das instituições de saúde em relação às outras empresas está na presença de várias culturas no ambiente de trabalho. Nelas atuam grupos de pessoas de profissões distintas e com objetivos diferentes. E isso gera um grupo de poder, liderado pelo médico. Geralmente, esse grupo tem peso e prestígio no hospital, apesar de não ter poder e autoridade formal sobre todo o hospital. Mesmo assim, a cultura existente nessas organizações confere "poder" ao médico, o qual, praticamente, é considerado detentor do conhecimento necessário para a execução da função básica do hospital: o atendimento ao paciente.

Nessa cultura de dominação médica, o pessoal paramédico exerce diversas profissões distintas. Mas, apesar de sua importância no funcionamento do hospital, esses profissionais não detêm parcela importante de poder. Assim, pode-se constatar que existe uma multiplicidade de grupos atuando dentro e fora do hospital, com interesses e objetivos diferentes. Por conta disso, às vezes, nessa instituição, gera-se uma "guerra cultural", a qual pode evidenciar a existência de processos que exigem mudanças.

Finalmente, deve ser destacado aqui que os distintos tipos de instituições de saúde, incluindo-se os hospitais públicos, privados e a rede básica de saúde os quais possuem configurações organizacionais específicas, apesar disso, compartilham algumas características similares, a exemplo da autonomia dos médicos e da centralização do poder hierarquizado dessas organizações. As implicações desse modelo de atenção médico-hospitalar podem comprometer as necessidades de atenção à saúde da população. Portanto, são aspectos político-institucionais e culturais importantes a serem considerados no contexto das instituições de saúde.

As instituições de saúde se caracterizam por ter uma função básica, que é atender as necessidades de saúde das pessoas. Para isso, dispõem de uma estrutura constituída por profissionais que possuem um conjunto de crenças, valores, idéias e comportamentos comuns, embora às vezes divergentes, bem como relações reguladas por normas e procedimentos. Na realidade, a instituição de saúde é um fenômeno cultural que varia, conforme o estágio de desenvolvimento da comunidade da qual faz parte ${ }^{(14)}$. Pode-se afirmar que as instituições de saúde são fenômenos sociais abstratos. Por sua vez, o hospital ou a unidade de saúde é a sua manifestação mais concreta, com características bem definidas em razão de suas peculiaridades.

\section{A IDENTIDADE DO SUJEITO NA ORGANIZAÇÃO}

A organização é constituída por um conjunto de pessoas, aqui denominadas de sujeitos (indivíduo portador de determinações e que é capaz de propor objetivos e praticar ações). O termo "identidade" deriva dos vocábulos latinos idem e identitas, que significam "o mesmo". Outro termo importante nesse contexto é self, que pode ser entendido como "o eu de cada um". Assim, a identidade tem relação com um conteúdo ou propriedade, enquanto o self representa a entidade que a incorpora ${ }^{(15)}$.

A identidade pode ser conceituada como um estado psicossocial, que pode variar no tempo, não sendo, portanto, fixo. Isso significa que pode se referir ao indivíduo, ao grupo ou à sociedade. Ora, o sujeito tem diversas identidades e o conjunto delas lhe permite experimentar um sentimento de identidade. Assim, um núcleo identitário é a fonte de coerência interna que caracteriza um ser que tem consciência da própria existência ${ }^{(16)}$.

Em outro contexto, o termo identificação social refere-se às características que são atribuídas a um indivíduo pelos outros. Elas podem ser vistas como marcadores que indicam quem é, em um sentido básico, essa pessoa. Ao mesmo tempo, esses marcadores posicionam essa pessoa em relação a outros indivíduos que compartilham dos mesmos atributos $^{(17)}$. São exemplos de identidades sociais o estudante, a mãe, o advogado, o católico, o sem-teto, o asiático, o disléxico, o casado e assim por diante. Muitos indivíduos têm identidades sociais que compreendem mais do que um atributo.

O grau de identificação é sempre variável, na medida em que evidencia o caráter dos vínculos sociais, da captação e da ligação entre a pessoa e os objetos. Isso inclui a empresa, o chefe e os colegas, além do trabalho em $\mathrm{si}^{(16)}$. As normas do grupo, os seus valores e as suas condutas são interiorizados 
progressivamente. No entanto, a identidade em si não tem o mesmo sentido de identidade social, vista que nesta estão incluídos os atributos pessoais, as fantasias, as posses, a vida familiar, os relacionamentos e os sentimentos relacionados a todas essas variáveis simbólicas de que o indivíduo faz uso para se conceituar e se situar no mundo.

$\mathrm{Na}$ atualidade, questões relacionadas à identidade cultural, ao sujeito e suas relações têm merecido especial atenção, principalmente nas instituições de saúde. Essas questões são consideradas mais profundamente, tendo em vista a globalização e a emergência da sociedade da informação em que vivemos. Há um rápido ajustamento de antigas identidades que foram deslocadas em direção ao que os teóricos chamam de um sujeito pós-moderno. Assim, o sujeito anteriormente considerado como tendo uma identidade unificada e estável está se tornando fragmentado composto não de uma única, mas de várias identidades, algumas vezes contraditórias ou não resolvidas ${ }^{(18)}$.

Isso significa que a identidade não é fixa nem imutável. Convém esclarecer que os processos de identificação podem ser mais intensos em determinados períodos da vida dos indivíduos. Tal intensidade não exclui a multiplicidade de pessoas existentes em nós, já que somos resultado de uma pluralidade de pessoas com as quais convivemos e nos vamos identificando ao longo de nossas vidas ${ }^{(19)}$. Nessa perspectiva, a identidade dos indivíduos é uma síntese de múltiplas identificações, que vão ocorrendo em função da vinculação a diferentes grupos sociais, a exemplo da família, da escola, da empresa e outras instituições. Em resumo, as possibilidades de identificação são ilimitadas e não há nenhuma âncora que as retenha ${ }^{(20)}$.

O fato de os indivíduos terem identidades múltiplas contribui para a complexidade da identidade nas instituições de saúde. Os indivíduos não são apenas homens, mulheres, negros ou brancos. As identidades se cruzam para criar uma identidade multifacetada. As formas como os sujeitos interagem ou se destacam são importantes para o contexto das instituições de saúde. A identidade precisa ser compreendida como sendo constituída por quatro níveis de análise: individual, grupal/intergrupal, organizacional e social ${ }^{(21)}$. A partir da análise desses níveis, evita-se a tendência de se atribuir determinada mudança apenas aos membros da organização, bem como a hipótese de que os efeitos negativos das identidades sejam originados nos deficientes processos cognitivos dos indivíduos.

Portanto, nas instituições de saúde devem ser observados os fatores que afetam e moldam a identidade, como uma nova legislação, o desenvolvimento político, mudanças, dentre outros. A identidade pode ser vista sob duas dimensões: a) imagem: como a organização é vista por quem com ela interage; b) auto-imagem: como indivíduos se percebem e percebem a organização. Pode também surgir da razão de ser, da finalidade ou do propósito do grupo de indivíduos, de modo que a identidade representaria esse propósito existencial. A identidade é uma marca reconhecível quer pelos que participam da organização quer pelos que com ela interagem ${ }^{(21)}$.

\section{O PAPEL DA CULTURA INDIVIDUAL NAS INSTITUIÇÕES DE SAÚDE}

A cultura tem um papel fundamental na vida das organizações. Isso se explica pelo fato de que as organizações são constituídas de pessoas que vivem em constante interação simbólica umas com as outras. Nessa interação, elas estabelecem uma conduta coletiva, ou seja, um universo simbólico que serve de referência e, além disso, direciona comportamentos, atitudes e ações. Estudar a cultura da organização, a partir dessa perspectiva, permite perceber como as pessoas interpretam e compreendem suas experiências.

Por outro lado, os fenômenos culturais que ocorrem no interior de uma instituição de saúde são permeados por distintos campos de saber e domínios teóricos. Por isso, para sua compreensão, eles exigem, em tese, a articulação de conceitos da História, Sociologia, Antropologia, Ciência Política, Administração etc., uma vez que a cultura pode referir-se a várias dimensões do simbólico. Tal categoria é bastante conhecida na área da saúde, a exemplo da antropologia médica e suas representações sobre saúde-doença. Ela vem sendo muito utilizada quando se fala de organizações e instituições como uma chave polissêmica que, nem sempre, discrimina o que está sendo aplicado.

Na realidade, não existe apenas uma definição de cultura. Em se tratando de conceito que se institui como eixo disciplinar da Antropologia, suas definições vêm acompanhando as próprias transformações e disputas no interior desse campo. Por outro lado, se cultura for entendida como um sistema de significados que cria algum tipo de identidade compartilhada, uma espécie de código que orienta as práticas sociais de pessoas que pertencem a vários grupos e categorias 
sociais dentro de uma sociedade, essa definição deve ser ajustada aos tipos de fenômenos particulares que se pretende analisar. É possível fazer um recorte do fenômeno ou problema relativo à cultura em uma organização de saúde, a partir de sua pertinência a distintas dimensões, tais como cultura política, cultura cívica, cultura organizacional e cultura profissional ${ }^{(22)}$.

As instituições de saúde caracterizam-se por apresentar um determinado padrão de interação entre seus membros. Essa característica é produto de uma história social, política e, até mesmo, cívica que as configura de forma diferenciada daquela das organizações industriais. A cultura de uma determinada organização pode ser entendida como um sistema de significados compartilhados pelos seus membros, o qual configura uma identidade coletiva ${ }^{(22)}$. As organizações de saúde são marcadas pela maneira como foram criadas as relações entre o saber médico (ciências médicas) e a sociedade, assim como as relações dos sujeitos (profissionais da saúde) com a instituição.

A complexidade que se apresenta na análise desse tema mostra que a cultura organizacional é considerada como uma espécie de "mini-sociedade", na qual se constrói um sistema de significados próprios $^{(23)}$. Em outras palavras, essa análise envolve valores, crenças, pressupostos, percepções, normas e padrões de comportamento, muitas vezes, não perceptíveis. Significa que não são facilmente observados ou apreendidos, embora estejam presentes. Quando essas configurações da instituição de saúde são compreendidas pelo gestor, seus membros podem ser mobilizados para agir em determinadas direções, conforme as diretrizes que norteiam a gestão organizacional.

Por outro lado, pode-se imaginar que as organizações de saúde são configuradas por uma rede de relacionamentos construídos ao longo da sua história social como instituição prestadora de serviço à sociedade. Portanto, incorporam elementos da própria sociedade a que serve, porque estão inseridas num ambiente social, incluindo-se aí as dimensões políticas, culturais e éticas.

Quando o sujeito sente-se pertencente a uma organização, cria-se uma identidade coletiva, conforme as características que a organização apresenta. Porém, deve-se considerar que, no plano corporativo, os profissionais da saúde adquirem uma identidade individual que traz implicações na questão da ética profissional, em termos das relações entre as categorias da área de atenção à saúde (relações entre médicos e terapeutas ou médicos e outros profissionais: enfermeiros, psicólogos, assistentes sociais, etc). Nessa identidade, também deve ser destacada a questão das relações entre profissionais da saúde e cidadãos usuários, caracterizadas muitas vezes por conflitos ou hostilidades e, em algumas situações, por falta de atendimento médico.

É preciso salientar ainda que, quando se faz um estudo sobre as organizações de saúde na sociedade atual, o aspecto cultural deve ser um ingrediente privilegiado pela análise de gerentes e planejadores. Com isso, podem traçar políticas públicas adequadas para a melhoria do atendimento médico-hospitalar.

\section{CONSIDERAÇÕES FINAIS}

O estudo das instituições de saúde sugere que cultura, poder e identidade estão intimamente relacionados, de forma que um desses aspectos pode fornecer significado ao outro. Uma cultura organizacional é capaz de reafirmar os valores e ideologias de um grupo em relação aos demais, constituindo a base desse grupo. Portanto, a cultura pode conceder poder e, conseqüentemente, alimentar as identidades dos membros de uma organização.

Nas instituições de saúde, o poder serve para sustentar a identidade que se torna legitimada pela sociedade. Todavia, o seu propósito é definir a identidade dos sujeitos, embora o seu efeito torne-os subordinados e inseguros quanto ao desempenho. Isso acontece porque há uma rede de interesses camuflados, desejos de confirmar sua subordinação ou os significados e sentimentos de superioridade dos detentores do poder nas organizações de saúde - o domínio do saber médico - tema brilhantemente analisado por Michel Foucault.

As instituições de saúde não têm dado atenção às questões relacionadas à identidade cultural na organização, com seus rituais e cerimônias. Uma das características desse contexto é que os gestores têm sua legitimidade enfraquecida, reduzindo-se também a justificativa de seu poder. Neste aspecto, as identidades sociais e pessoais, que estão baseadas em papéis, são interdependentes. Em razão disso, os papéis sociais podem afetar a individualidade, especialmente quanto à auto-imagem, ao reconhecimento e à estabilidade, em virtude de sua inserção no contexto das relações sociais e de poder. Nas instituições de saúde, isso é percebível 
quando se observa o poder dos médicos em detrimento dos demais profissionais da saúde, a exemplo do Ato Médico (PLS 025/2002). Trata-se de um projeto elaborado, de forma corporativista, por alguns setores da medicina, ainda em tramitação no Congresso Nacional.

Em suma, as instituições de saúde são possuidoras de significados para os diversos profissionais que atuam nessa área, possibilitando-lhes conquistas pessoais. Evidentemente, se a organização desenvolver uma cultura no sentido de oportunizar avanço na carreira profissional, propiciará satisfação aos empregados. Todavia, se não for preenchida essa expectativa ou se as pessoas sentirem que sua identidade foi diminuída com o surgimento de nova cultura, provavelmente a organização comprometerá seus valores. Assim, quando o gestor utiliza a cultura organizacional para integrar e alcançar unidade, isso pode ter um efeito negativo, como, por exemplo, estimular a formação de subculturas e o descomprometimento do indivíduo. Portanto, uma cultura organizacional só pode ser entendida e fomentada dentro de uma dimensão relacional e política. A identidade e a cultura interagem na demarcação de um campo simbólico propício para a reprodução mútua.

\section{REFERÊNCIAS}

1 Alvesson M, Berg PO. Corporate culture and organizational symbolism. New York: Walter de Gruyter; 1992.

2 Fineman S. Emotion in the organizations. London(GB): Sage; 1994.

3 Bastos MAR. A temática cultural organizacional nos estudos na área da saúde e da enfermagem. Rev Latino-am Enferm. 2001 Jul;9(4):68-74.

4 Turner BA. Sociological aspects of organizational symbolism. Organization Studies. 1986;7(12):101-15.

5 Clegg SR. Postmodern management? An inaugural address to the University of St. Andrews: St. Andrews; 1992.

6 Barbosa L. Cultura administrativa das relações entre antropologia e administração. Rev Adm Empresas. 1996;36(4):6-19.

7 Freitas ME. Cultura organizacional, tipologias e impactos. São Paulo: McGraw Hill; 1991.

8 Souza ELP. Clima e cultura organizacionais: como se manifestam e como se manejam. São Paulo: Edgar Blucher; 1978.

9 Schein E. Cultura organizacional e liderança. USA: Jossey Bass Publishers; 1995.

10. Silva N. As interseções entre cultura e aprendizagem organizacional. Convergência - Rev Ciências Sociales. 2001 Sept/Dec;8(26):55-76.

11 Schein E. Organizational culture. Am Psychol;1990.

12 Scott C. Visão, valores e missão organizacional. Construindo a organização do futuro. Rio de Janeiro: Qualitymark; 1998.

13 Schein E. Psicologia organizacional. Rio de Janeiro: Prentice-Hall; 1992.

14 Morgan G. Imagens da organização. São Paulo: Atlas; 1996.

15 Caldas MP, Wood Júnior T. Identidade organizacional. Rev Adm Empresas. 1997;37(1):6-17.

16 Freitas ME. Cultura organizacional, identidade, sedução e carisma? Rio de Janeiro: FGV; 2000.

17 Giddens A. Sociologia. Rio de Janeiro: ArtMed; 2005.

18 Hall S. A identidade cultural na pós-modernidade. Rio de Janeiro: DP\&A; 2002.

19 Maffesoli M. O tempo das tribos. São Paulo: Forense Universitária; 1998.

20 Placer FG. Identidade, diferença e indiferença: o si mesmo como obstáculo. In: Larrosa J, Lara NP, organizadores. Imagens do outro. Petrópolis: Vozes; 1998.

21 Nkomo SM, Cox Júnior T. Diversidade e identidade nas organizações. In: Clegg SR, Hardy C, Nord WR. Handbook de estudos organizacionais: reflexos e novas direções. São Paulo: Atlas; 1990. v.1.

22 Vaitsman J. Cultura de organizações públicas de saúde - notas sobre a construção de um objeto. Cad Saúde Publ. 2000 Jul/Set;16(3):847-50.

23 Ott S. The organizational culture perspective. Pacific grove: Brooks/Cole Publishing; 1989. 